\title{
External transport pricing and modal choice: evidence from a Paris case study
}

\author{
A. de Palma \& N. Zaouali \\ University of Cergy-Pontoise THEMA, France
}

\begin{abstract}
Many European studies have shown that prices paid by transport users do not cover the real cost of moving. Some costs related to pollution, congestion, noise and accidents are covered partially. The external costs caused by travel using public transport are lower than using cars. This deduction has pushed many authorities to encourage the transfer of passenger traffic from private car to public transport. The purpose of the present study is to estimate the impact of some external costs pricing on the commuters' modal split between car and public transport. We have used two pricing schemes: exogenous toll and marginal social cost pricing. To put it into practice, we estimate Multinomial Logit (ML). On the other hand, ML has a critical assumption related to the Independence from Irrelevant Alternatives. In order to relax this property we recast the model as a nested structure. We simulate these prices' scenarios through a Nested logit model. Therefore we estimate the choice probabilities, thus we calculate the welfare gains. The aim results of this paper indicate that prices paid by transport users must reflect marginal external costs (mec). For the exogenous toll, the welfare gains are relatively small. This finding is not surprising because taxes are below the mec. For the marginal social cost pricing, all taxes are corrected so as to equal the mec; the welfare gain is estimated at $0.61 \%$. We can also notice that a part of the reduction in car use is due to its substitution for public transport.
\end{abstract}

Keywords: external costs, pricing, modal choice, discrete choice models.

\section{Introduction}

During these last decades many European studies on transport, green paper 1995 [1] and white paper 1998 [2], have shown that fees and taxes have been arbitrarily fixed. In fact, prices paid by the transport users do not cover the real 
cost of moving. Some costs related to pollution, congestion, noise and accidents are covered partially or not at all. In order to find answers to these enquiries, "The Green Paper, 1995" examines trip costs in detail. However, we can distinguish between two types of costs: -Private costs that are directly charged to the person who benefits from transport facilities (fuel costs, vehicle and parking costs and ticket cost for public transport), -External costs which are not taken in charge by users (congestion costs, pollution costs, noise costs and accidents' costs). The external costs resulting from travel using Public Transport (PT) are lower than the costs of using Private Car (PC). At Ile-de-France, PC contributes up to $25.585 € / 1,000$ veh.km, while accidents reach $34.83 € / 1,000$ veh.km, and noise is estimated at $4.095 € / 1,000$ veh.km. For PT, pollution is estimated at $2.5 € / 1,000$ veh.km, accidents at $2.3 € / 1,000$ veh.km and noise at $2.96 € / 1,000$ veh.km (Quinet [3] and UNITE [4]). This deduction has pushed many authorities to make their pricing systems fairer and more efficient, and to encourage the transfer of passenger traffic from PC to PT, that entails fewer negative effects on society. From an economic point of view, the very existence of external costs produces a discrepancy between private costs and social costs. Therefore, the equilibrium that is reached on the transportation market does not correspond to the optimal situation. In the economic literature, external costs' pricing refer to the studies carried by Pigou [5], Knight [6], Walters [7] and Vickrey [8]. They demonstrated that, in order to maximise social welfare, the taxes of external costs internalisation have to be calculated on the basis of marginal social costs.

The purpose of the present study is to estimate the impact of some pricing policies on the commuters' modal split between PC and PT. Nevertheless, up to now no econometric study has ever examined the impact of external costs pricing through a discrete choice models at Ile-de-France. To accomplish this we have used two pricing instruments, exogenous toll and marginal social cost pricing, that vary across times and modes. Both pricing instruments that have been used in this paper are the results of a European study entitled "Reforming transport taxes, 2003" [9] which has been carried out by the European Conference of Transport Ministers together with the General Direction of Energy and Transports of the European Commission. Our study covers passenger transport between a residential area and a workplace in Paris. People from Ile-deFrance make use of the RER, metro, train, bus and car. In order to achieve this study, we used two databases: Global Transport Survey and the simulation results of the IAURIF (Institut d'Aménagement et d'Urbanisme de la Région d'Ile-de-France) model [10]. To put it into practice, we estimate a Multinomial Logit (ML) model for a group of users based on gender, age, geographic variables, travel time and private travel cost. On the other hand, ML has a critical assumption related to the Independence from Irrelevant Alternatives. In order to relax this property we recast the model as a nested structure. We simulate these prices' scenarios through the Nested Logit (NL) model; travel cost includes private travel cost and toll. Therefore we estimate the choice probabilities for each transport modes (private car, rail and bus) and at each trip periods (peak period and off-peak period), thus we calculate the welfare gains. 


\section{Data and methodology}

In this paper, we'll focus on a case study in Ile-de-France. This choice is because of the region's significant role in the national economy. In fact, it represents an important economic activity (28\% of the GNP), and includes various employment categories. The surface of Ile-de-France is $12,000 \mathrm{~km}^{2}$, with 10 million inhabitants which represents $18 \%$ of the French population. We are here presenting a case study on Paris area. This region is known as "Ile-de-France" which is divided into 8 districts: Paris, 3 districts around it named as close suburb and 4 further districts far away from Paris as far suburb.

This analysis rests on the individual data and the discrete choice models (ML model and NL model). The models that have been used, allow us to estimate the impact of some pricing policies on the choice probabilities for each mode. For this purpose, we make use of two data sources: Global Transport Survey (GTS) and the simulation results of IAURIF.

This questionnaire (GTS) brought about three types of information: it includes data related to the household's characteristics such as its location, its income and its motorisation. We also find the different features of the household's members: age, gender, workplace, residential area, social class, etc. as well as information related to their moving: departure time, arrival time, transport modes, trip intentions, the origins and destinations. In this study we make use of a sample on the travels by PC and PT, as trip intentions whether residential area/workplace or residential area/business activities. According to the global transport survey, the travel time has some constraints. This survey permits us to measure the travel time for each passenger which depends on the modes of transport that have been used. We also have another source of information from which we can get the travel time of the alternating modes, between the same origin and destination. These are the simulations results of the IAURIF model. The model that has been elaborated by IAURIF is a four stage model. It takes into account both the private transport and the collective one, and it uses a regional division of Ile-de-France for 522 zones (80 of which are in Paris). The road and the public transport networks have been extracted from the Occupation Model of the IAURIF. The road network includes the motorways, express ways, national and departmental roads, etc. We mean by the rail system the heavy network (SNCF and RATP) and the major bus routes. The total system extends over 2,900 links and 1,000 nodes. At the end of the affectation, the IAURIF model provides the travel time by PC and PT for each origindestination.

To establish a choice model of a travel mode, that serves to go to the workplace, we notice the following explanatory variables: the cost affecting the passenger, the travel time and a vector of persons' own characteristics. Using these two data bases, we have calculated the cost and the travel time. For PC, the cost is determined in terms of the achieved distance, multiplied by a kilometre cost $0,4 € / \mathrm{km}$ STIF [11]. For a PT, the cost is that of a monthly ticket "Carte Orange". The travel time of the PC includes the real time of the route and the time of looking for a place in a parking. As for the PT the total travel time is the 
sum of the route time for public transport, waiting time, transfers, access and distribution time. Tablel shows the principal variables that have been used for the choice mode model estimations. From these two data bases, we estimate a choice mode model (ML and NL models). Then, we simulate two prices' scenarios, and we estimate a choice probability for a given mode as well as the welfare gain. These pricing policies result from the simulation of the TRENEN model (Ochelen and Proost [12]) on many European regions, the Ile-de-France is a case in point. This model consists in looking for the optimal pricing policies and regularization policies in transport and environment. This is to be carried out through optimising a welfare function.

Table 1: $\quad$ Variables description.

\begin{tabular}{|c|c|}
\hline variables & Description \\
\hline gender & $\begin{array}{l}=1 \text { if man } \\
=2 \text { if woman }\end{array}$ \\
\hline age & $\begin{array}{l}=1 \text { if age } \in[6 \text { years, } 24 \text { years }] \\
=2 \text { if age } \in[25 \text { years, } 54 \text { years }] \\
=3>55 \text { years }\end{array}$ \\
\hline social class & $\begin{array}{l}=1 \text { if user is a farmer, artisan or manager } \\
=2 \text { for professions } \\
=3 \text { if user is an employee or student } \\
=4 \text { retired person }\end{array}$ \\
\hline annual income & $\begin{array}{l}=1 \text { if income } \in[€ 4,573 ; € 18,294[ \\
=2 \text { if income } \in[€ 18,294 ; € 36,588[ \\
=3 \text { if income } \geq € 36,588\end{array}$ \\
\hline trip periods & $\begin{array}{l}=1 \text { if trip made between 7:00-9:30 AM and/or 5:00-7:00 } \\
\text { PM (peak hour) } \\
=0 \text { otherwise (off-peak hour) }\end{array}$ \\
\hline mode & $\begin{array}{l}=1 \text { if mode used is metro, RER, suburban SNCF or bus } \\
=2 \text { if passenger uses private car }\end{array}$ \\
\hline travel time $(\mathrm{min})$ & In-vehicle travel time \\
\hline parking time & Time of looking for a place in a parking \\
\hline waiting time & Time made to wait in a public transport station \\
\hline transfer time & Time made to transfer in public transport \\
\hline access time & $\begin{array}{l}\text { Access time between workplace (or residential area) and } \\
\text { public transport station }\end{array}$ \\
\hline
\end{tabular}

\section{Estimation of a mode choice models}

\subsection{The model formulation}

Our research revolves around three trip modes: rail, bus and private car. According to the results of the global transport survey, people from Ile-de- 
France admit using the following transport modes to go to their work: SNCF, RER, metro, SNCF+ metro/RER, RER + metro, urban bus and private car. We can classify these modes into three sub-modes: the rail system includes RER, $\mathrm{SNCF}$, metro, RER+ metro and SNCF+ metro/RER; the bus pertains to moving by urban bus and the third one includes moving by private car. Within the realm of transport, the logit model is a model that reflects at best the distribution of various competing modes. Now, we are presenting the formulation and characteristics of these models. The ML model is a discrete-choice model which is based on the maximisation of utility functions. Each passenger $i$ chooses the mode $j$ which provides him the maximum utility. In fact, the utility function related to $j$ mode is written as follow:

$$
U_{i j}=V_{i j}+\varepsilon_{i j}
$$

This utility function $U_{i j}$ is composed of two terms: the observed element $V_{i j}$, which is a linear combination of the modes attributes $j$ (like the travel time $t t_{j}$ and the travel $\operatorname{cost} c_{j}$ ) and the passenger's socioeconomic characteristics $x_{i}$ (like age, income, gender, social class, etc.), the unobserved element $\varepsilon_{\mathrm{ij}}$, which corresponds to the unobserved variables, affecting the individual choices. Hence, the utility function would be written as follows:

$$
U_{i j}=\alpha t t_{j}+\beta c_{j}+\gamma x_{i}+\varepsilon_{i j}
$$

According to a Weibul's hypothesis, the error terms are supposed independently and identically distributed, McFadden [13] has shown that the probability that an individual $i$ chooses the mode $j$, takes the following form:

$$
P_{i j}=\frac{\exp \left(\alpha t t_{j}+\beta c_{j}+\gamma x_{i}\right)}{\sum_{k=1}^{3} \exp \left(\alpha t t_{k}+\beta c_{k}+\gamma x_{i}\right)}
$$

Although, this model is the most used of all discrete choice models for its simple and intuitive formulation, it has some limits. Indeed, it has the property that the ratio probabilities of each pair of alternatives are independent of the characteristics of any third alternatives. This is the Independence from Irrelevant Alternatives (IIA). This assumption implies that the relative probabilities of two alternatives being selected must be unaffected by the introduction or the elimination of other alternatives. However, the test of IIA, Hausman and McFadden [14], often fails. In order to relax this limit, we suggest the use of a Nested Logit model. In this approach, we consider the choice process as that of a multiple-step choice. Here, we consider the specification as a two-level choice. A first choice has to be done between public transport and private car. Then, a second choice will be made between sub-groups (the rail, bus and private car). 
The choice probability of sub-mode $s m$ is written as follows:

$$
P_{s m}=P_{s m / m} \times P_{m} \text { where } P_{s m / m}=\frac{\exp \left(\alpha t t_{s m}+\gamma x_{s m}\right)}{\sum_{r=1}^{s m} \exp \left(\alpha t t_{r}+\gamma x_{r}\right)} .
$$

However, the choice probability of mode $m$ is given by:

$$
P_{m}=\frac{\exp \left(\theta I_{m}+\beta c_{m}\right)}{\sum_{k=1}^{m} \exp \left(\theta I_{k}+\beta c_{k}\right)}
$$

Thus, we define an inclusive value marked $I_{m}$. It equals $I_{m}=\log \left(\sum \exp \left(\alpha t t_{j}+\gamma x_{i}\right)\right)$. The estimated coefficient $\theta$ of the inclusive value belongs to the interval] $0,1[$. It is a necessary condition for the NL model (McFadden [15]). Whereas, if $\theta=0$ or $\theta=1$, the NL model is equivalent to the ML model. Then, we write this probability as:

$$
P_{s m}=\frac{\exp \left(\alpha t t_{s m}+\gamma x_{s m}\right) \times \exp \left(\theta I_{m}+\beta c_{m}\right)}{\exp \left(I_{m}\right)+\sum_{k=1}^{m} \exp \left(\theta I_{k}+\beta c_{k}\right)}
$$

\subsection{The empirical results}

Table 2 contains the results of the mode choice model estimation, namely the Multinomial Logit and the Nested Logit models. For Multinomial Logit model, the $\mathrm{R}^{2}$ McFadden is 0.294 . We note that the travel cost and the travel time have a negative impact on mode choice. The estimation coefficients of these variables confirm the precedent result: they are negative and highly significant. This shows that price gives citizens incentives to find solutions to transport problems. From these empirical results, we conclude that passenger from social class 1 and social class 2 use more private car than public transport. Finally, we observe that the variables related to the residential area and to the workplace give an important effect on mode choice. In fact passengers who live in Paris use public transport to go to work. This choice is essentially due to the high congestion costs in Paris during the peak hours.

The estimated coefficients from the Nested Logit model provide information about the effect of variables on the mode choice within each nest. Although inclusive value is equal to 0.3919 and $\mathrm{R}^{2}$ _McFadden is estimated to 0.6489 . This finding suggests that the nested structure is appropriate. As in the Multinomial Logit results, the trip variables, the location variables and the social class variables appear more important in the determining of the mode choice. 
Table 2: $\quad$ Estimation results.

\begin{tabular}{|c|c|c|}
\hline & ML & $\mathrm{NL}$ \\
\hline variables & \multicolumn{2}{|c|}{ coefficients } \\
\hline $\begin{array}{l}\text { cost } \\
\text { time }\end{array}$ & $\begin{array}{c}-0.00282 * * \\
-0.014 * * *\end{array}$ & $\begin{array}{l}-0.00488^{* *} \\
-0.0246 * * *\end{array}$ \\
\hline $\begin{array}{l}\text { man_pc } \\
\text { wom pc }\end{array}$ & $\begin{array}{l}0.3235 \\
0.2203\end{array}$ & $\begin{array}{c}0.1645 \\
-0.1231\end{array}$ \\
\hline $\begin{array}{l}\mathrm{sc} 1 \_\mathrm{pc} \\
\mathrm{sc} 2 \_\mathrm{pc} \\
\mathrm{sc} 3 \_\mathrm{pc}\end{array}$ & $\begin{array}{c}0.6427 * \\
1.2402 * * * \\
0.3433\end{array}$ & $\begin{array}{l}1.4236 * \\
1.0677 * \\
-0.1704\end{array}$ \\
\hline $\begin{array}{l}\text { income1_pc } \\
\text { income } 2 \_ \text {pc }\end{array}$ & $\begin{array}{l}-1.2385 * * * \\
-0.4861 * *\end{array}$ & $\begin{array}{c}-3.3184 * * * \\
-1.078 * *\end{array}$ \\
\hline $\begin{array}{l}\mathrm{sc1} \text { _rail } \\
\mathrm{sc} 2 \text { rail } \\
\mathrm{sc} 3 \text { _rail }\end{array}$ & $\begin{array}{c}-0.1724 \\
1.1762 * * * \\
0.3874 * *\end{array}$ & $\begin{array}{c}-0.8084 * * \\
0.5455^{* *} \\
-0.3088\end{array}$ \\
\hline $\begin{array}{l}\text { income1_rail } \\
\text { income3_rail }\end{array}$ & $\begin{array}{c}0.2398^{*} \\
0.0565\end{array}$ & $\begin{array}{c}0.1889 \\
-0.001816\end{array}$ \\
\hline $\begin{array}{l}\text { p_p_pc } \\
\text { p_gc_pc } \\
\text { pc_p_pc } \\
\text { pc_gc_pc } \\
\text { gc_p_pc } \\
\text { gc_gc_pc }\end{array}$ & $\begin{array}{c}-1.4133 * * * \\
-3.0839 * * \\
-0.1458 \\
-2.0396 * * * \\
-1.0021 * * * \\
-1.5909 * * *\end{array}$ & $\begin{array}{l}-3.639 * * * \\
-7.6529 * * \\
-1.5517 * * \\
-5.1615 * * * \\
-2.6261 * * * \\
-2.7289 * * *\end{array}$ \\
\hline $\begin{array}{l}\text { p_pc_rail } \\
\text { p_gc_rail } \\
\text { pc_p_rail } \\
\text { pc_gc_rail } \\
\text { gc_gc_rail } \\
\text { gc_pc_rail }\end{array}$ & $\begin{array}{c}0.4422 * * \\
-0.6999 \\
0.782 * * * \\
0.0557 \\
-0.6848 * * \\
0.7823 * * *\end{array}$ & $\begin{array}{c}0.0452 \\
-1.1835 * * \\
0.7636 * * * \\
-0.3857 \\
-0.8321 * * \\
0.9793 * * *\end{array}$ \\
\hline Inclusive value & - & $0.3919 * * *$ \\
\hline $\mathrm{R}^{2}$ McFadden & 0.294 & 0.6489 \\
\hline$* * *$ : significant at $1 \%$ & $* *$ : significant at $5 \%$ & $*$ : significant at $10 \%$ \\
\hline
\end{tabular}

\section{Policies and simulations}

We estimate the impact of some external costs pricing on the commuters modal split between car and public transport. In this study, we used two pricing schemes: exogenous toll and marginal social cost pricing (optimal scenario). The optimal pricing results have been found in the TRENEN model within a European study entitled "Reforming transport taxes, 2003". It is, actually, the addition of the price $p_{j}$ to the trip cost. Therefore, the utility function would be written as follows: 


$$
U_{i j}=\alpha t t_{j}+\beta\left(c_{j}+p_{j}\right)+\gamma x_{j}+\varepsilon_{i j}
$$

As previously explained, the reference situation has been found out from our data base, namely the modal distribution at unchanged pricing policies. We first discuss the reference situation. Then, we show the simulation results, namely the commuters' modal split between car and public transport, and the welfare gain.

\subsection{Description of the reference situation}

The following table shows the distribution of people from Ile-de-France over the transport modes. In fact, $63.01 \%$ of the trip is done by private car. But we notice that during peak hours (from 7:00 am to 9:30 am and/or from 5:00 pm to 7:00 pm) $43.37 \%$ of passengers use their private car to go to work whereas $27.87 \%$ take public transport.

Table 3: $\quad$ Reference situation

\begin{tabular}{|l|c|}
\hline Mode & Modal distribution \\
\hline Private car, peak hour & $43.37 \%$ \\
\hline Private car, off-peak hour & $19.64 \%$ \\
\hline Bus, peak hour & $1.52 \%$ \\
\hline Bus, off-peak hour & $0.80 \%$ \\
\hline Rail, peak hour & $26.35 \%$ \\
\hline Rail, off-peak hour & $8.32 \%$ \\
\hline
\end{tabular}

\subsection{The interpretation of Ile-de-France exogenous pricing}

A taxation has been imposed on passenger in 2000. In their travel by PC, users pay $0,113 €$ in peak hours and $0,096 €$ in off-peak hours. The peak hours taxation versus off-peak hours variation is due to an increase in external costs during rush hours $(0,242 € /$ pass.km). From this table we conclude that the marginal external cost is more significant for PC $(0,327 € /$ pass.km) while the PT makes up $0,054 € /$ pass.km. The simulations results of this policy represent a new passenger distribution over travel modes. The displacement percentage by PC during peak hours decreases $(39 \%)$. In fact, there is a substitution towards more PT use (rail: $30.03 \%$ and bus: $1.7 \%$ ). From these results, we notice an outstanding improvement in traffic conditions. However, the external costs are only partially covered. For instance, the PC marginal external cost in peak hours costs $0,242 € /$ pass.km, whereas the paid fee is $0,113 € /$ pass.km. Nevertheless, the prices that are paid by transport users do not cover the real cost of moving.

\subsection{The interpretation of Ile-de-France optimal pricing}

In this section, we discuss the optimal scenario. For this pricing policy, all taxes are corrected so as to equal the marginal external costs. For instance, the private car marginal external costs in off-peak hour reach $0,081 € /$ pass.km, whereas the prices that are paid by transport users are estimated at $0,17 € /$ pass.km. From these 
simulation results, note that during the peak period all prices rise. From private transport, this increase is essentially due to the high marginal external congestion costs in Paris area. Furthermore, observe that peak car traffic decreases from $43.37 \%$ to $36.20 \%$. A part of the reduction in car use is due to its substitution for public transport use. The welfare gain of this scenario is of the order of $0.62 \%$, whereas it appears to be very limited for the exogenous toll.

Table 4: $\quad$ Simulation results.

\begin{tabular}{|c|c|c|c|c|c|c|}
\hline & \multicolumn{3}{|c|}{$\begin{array}{c}\text { Exogenous toll } \\
€ / \text { pass.km }\end{array}$} & \multicolumn{3}{|c|}{$\begin{array}{c}\text { Optimal scenario } \\
€ / \text { pass.km }\end{array}$} \\
\hline Mode & price & $\operatorname{tax} * *$ & $\mathrm{mec}^{*}$ & price & $\operatorname{tax} * *$ & $\mathrm{mec}^{*}$ \\
\hline pc, peak & 0,553 & 0,113 & 0,242 & 0,75 & 0,31 & 0,195 \\
\hline pc, off-peak & 0,507 & 0,096 & 0,085 & 0,58 & 0,17 & 0,081 \\
\hline bus, peak & 0,175 & $-0,07$ & 0,028 & 0,27 & 0,017 & 0,023 \\
\hline bus, off-peak & 0,175 & $-0,08$ & 0,023 & 0,2 & $-0,05$ & 0,022 \\
\hline rail, peak & 0,081 & $-0,04$ & 0,001 & 0,13 & 0,006 & 0,001 \\
\hline rail, off-peak & 0,081 & $-0,01$ & 0,002 & 0,05 & $-0,05$ & 0,002 \\
\hline \multicolumn{7}{|c|}{ Simulation results: modal distribution (\%) } \\
\hline pc, peak & \multicolumn{3}{|c|}{$39 \%$} & \multicolumn{3}{|c|}{$36.20 \%$} \\
\hline pc, off-peak & \multicolumn{3}{|c|}{$19 \%$} & \multicolumn{3}{|c|}{$20 \%$} \\
\hline bus, peak & \multicolumn{3}{|c|}{$1.7 \%$} & \multicolumn{3}{|c|}{$2 \%$} \\
\hline bus, off-peak & \multicolumn{3}{|c|}{$0.87 \%$} & \multicolumn{3}{|c|}{$0.90 \%$} \\
\hline rail, peak & \multicolumn{3}{|c|}{$30.03 \%$} & \multicolumn{3}{|c|}{$31.30 \%$} \\
\hline rail, off-peak & \multicolumn{3}{|c|}{$9.40 \%$} & \multicolumn{3}{|c|}{$9.6 \%$} \\
\hline Welfare gain $(\%)$ & \multicolumn{3}{|c|}{0.32} & \multicolumn{3}{|c|}{0.62} \\
\hline \multicolumn{7}{|c|}{ *: Marginal External Cost (mec) } \\
\hline \multicolumn{7}{|c|}{ **: external cost taxation on Ile-de-France (€/pass.km), ECMT 2003} \\
\hline
\end{tabular}

\section{Conclusion}

We have analysed the impact of some external costs pricing on the commuters modal split between private car and public transport, through a discrete choice model. The important finding of this paper shows that prices paid by transport users must reflect the marginal external costs. We aim at reducing congestion, accidents and environmental problems. For the exogenous toll, the welfare gain appears to be very limited because taxes that are paid by transport users do not cover the real cost of moving. For the optimal scenario, the welfare gain is estimated at $0.61 \%$. The main reason is due to the reduction in the use of private car towards more public transport, which entails fewer negative effects on society. Finally, this study could be improved in many ways. The model can be applied on non-urban transport, at freight transport. We can also broaden the methodology of this paper with varied households' location. 


\section{References}

[1] Commission of the European Communities, Towards fair and efficient pricing in transport, Green Paper, 1995.

[2] Commission of the European Communities, Fair payment for infrastructure use: a phased approach to a common transport infrastructure charging framework for the EU, White Paper, 1998.

[3] Quinet, E., A meta-analysis of western European external costs estimates, Transportation Research, D 9, pp. 465-476, 2004.

[4] UNITE, Unification of accounts and marginal costs for transport efficiency, Competitive and sustainable programme, $5^{\text {th }}$ FrameworkTransport RTD, 2001.

[5] Pigou, A.C., The economic welfare, Macmillan: London, 1920.

[6] Knight, F., Some fallacies in the interpretation of social costs, Quarterly Journal of Economics, 38(4), pp. 582-606, 1924.

[7] Walters, A. A., The theory and measurement of private and social cost of highway congestion, Econometrica, 29, pp. 676-697, 1961.

[8] Vickrey, W. S., Congestion theory and transport investment, American Economic Review, 59, pp. 251-260, 1969.

[9] European Conference of Transport Ministers, Reforming transport taxes, 2003.

[10] IAURIF, Le modèle de trafic de l'IAURIF, Division Transports et Infrastructure, 1997.

[11] STIF, Compte transport de voyageurs de la région Ile-de-France, 2001.

[12] Ochelen, S. \& Proost, S., TRENEN urban model documentation prototype version 2.2. CES-KUL, Leuven mimeo, 1996.

[13] McFadden, D., Conditional Logit analysis of qualitative choice behaviour, Frontiers in Econometrics New York, Academic Press, pp. 105-142, 1974.

[14] Hausman, J. A. and McFadden, D., Specification tests for the multinomial logit model, Econometrica, 52, pp. 1219-1240, 1984.

[15] McFadden, D., (eds.) Econometric analysis of qualitative response models, Handbook of econometrics: Amsterdam, vol. II, 1984. 